\title{
Oxygen Barrier Properties and Melt Crystallization Behavior of Poly(ethylene terephthalate)/Graphene Oxide Nanocomposites
}

\author{
Anna Szymczyk, ${ }^{1}$ Sandra Paszkiewicz, ${ }^{2}$ Iwona Pawelec, ${ }^{1}$ Sławomir Lisiecki, ${ }^{3}$ Marek Jotko, ${ }^{3}$ \\ Zdenko Špitalský, ${ }^{4}$ Jaroslav Mosnáček, ${ }^{4}$ and Zbigniew Rosłaniec ${ }^{2}$ \\ ${ }^{1}$ Institute of Physics, West Pomeranian University of Technology, Piastow Avenue 19, 70310 Szczecin, Poland \\ ${ }^{2}$ Institute of Materials Science and Engineering, West Pomeranian University of Technology, Piastow Avenue 19, 70310 Szczecin, Poland \\ ${ }^{3}$ Center of Bioimmobilisation and Innovative Packaging Materials, Faculty of Food Sciences and Fisheries, \\ West Pomeranian University of Technology, Klemensa Janickiego Street 35, 71270 Szczecin, Poland \\ ${ }^{4}$ Polymer Institute, Slovak Academy of Sciences, Dúbravská Cesta 9, 84541 Bratislava 45, Slovakia
}

Correspondence should be addressed to Anna Szymczyk; aszymczyk@zut.edu.pl

Received 9 February 2015; Revised 18 May 2015; Accepted 24 May 2015

Academic Editor: Mircea Chipara

Copyright (C) 2015 Anna Szymczyk et al. This is an open access article distributed under the Creative Commons Attribution License, which permits unrestricted use, distribution, and reproduction in any medium, provided the original work is properly cited.

Poly(ethylene terephthalate) nanocomposites with low loading (0.1-0.5 wt\%) of graphene oxide (GO) have been prepared by using in situ polymerization method. TEM study of nanocomposites morphology has shown uniform distribution of highly exfoliated graphene oxide nanoplatelets in PET matrix. Investigations of oxygen permeability of amorphous films of nanocomposites showed that the nanocomposites had better oxygen barrier properties than the neat PET. The improvement of oxygen permeability for PET nanocomposite films over the neat PET is approximately factors of 2-3.3. DSC study on the nonisothermal crystallization behaviors proves that GO acts as a nucleating agent to accelerate the crystallization of PET matrix. The evolution of the lamellar nanostructure of nanocomposite and neat PET was monitored by SAXS during nonisothermal crystallization from the melt. It was found that unfilled PET and nanocomposite with the highest concentration of GO (0.5 wt\%) showed almost similar values of the long period ( $L=11.4 \mathrm{~nm}$ for neat PET and $L=11.5 \mathrm{~nm}$ for PET/0.5GO).

\section{Introduction}

Since the discovery in 2004 by Novoselov et al. [1], graphene has initiated a growing interest in using it as a filler to polymer materials. Graphene is a one-atom-thick, two-dimensional sheet composed of $\mathrm{sp}^{2}$ carbon atoms arranged in a plane structure [2], owning high intrinsic mobility $\left(2 \cdot 10^{5} \mathrm{~cm}^{2} / \mathrm{Vs}\right)$ $[3,4]$, excellent thermal conductivity $(2000-5000 \mathrm{~W} / \mathrm{m} \cdot \mathrm{K})$, extraordinary thermal stability [5-7], remarkable structural flexibility $[8,9]$ and large surface area [10], with mechanical strength (with Young modulus of $1 \mathrm{TPa}$ and ultimate strength of $130 \mathrm{GPa}$ [9]) approximately 100 times greater than steel, which makes graphene the strongest material ever measured. Because of such superior properties, graphene has attracted much attention for a wide range of applications, including nanocomposites [11-13], sensors [14, 15], field effect transistors [16], transparent conductive films [17], and many more. Graphene is not naturally abundant due to its instability and tendency to form three-dimensional structures (agglomeration). It can be synthesized by a variety of methods, such as chemical vapor deposition (CVD) [18, 19] arc discharge [20], epitaxial growth on $\mathrm{SiC}$ [21-23], chemical conversion [24], reduction of CO [25], unzipping carbon nanotubes [26, 27], and separation/exfoliation of graphite or graphite derivatives (such as graphite oxide (GO) and graphite fluoride) [28]. In addition, fast and low cost production of graphene and fewlayer graphene (FLG) with high yield, where the synthesis consisted of mechanical ablation of pencil lead on a harsh glass surface with simultaneous ultrasonication followed by a purification to remove the inorganic binder present in the pencil lead was demonstrated by Janowska et al. [29]. Among those methods, it has been proven that the reduction of exfoliated graphene oxide (GO) is a reliable strategy owing to its cost-effective and massive scalability. Generally, GO is obtained by oxidation of the natural flake graphite in the presence of strong oxidants such as potassium permanganate 
mixed with concentrated sulfuric acid, followed by sonication [30, 31]. After oxidation, abundant functional groups (e.g., hydroxyl, carboxyl, epoxy, and ketone) were introduced onto the graphitic layers, and simultaneously part of $\mathrm{sp}^{2}$-carbons were converted into $\mathrm{sp}^{3}$ ones [32]. It is generally considered that the epoxy and carbonyl groups are attached above and below basal planes, while the carboxyl groups are located at the edges $[33,34]$.

Incorporation of nanofillers into a polymer matrix gives rise to a new class of materials known as polymer nanocomposites, which have greater potential for many applications. Significant improvement in properties of the composites depends mainly on the size and shape of particles nanofiller [35], surface area, degree of surface development, surface energy, and the spatial distribution of the polymer matrix of nanoparticles. It is assumed that the degree of exfoliation plays the critical role in determining the nanocomposites properties. The more homogeneous dispersions of the layered nanofillers (expanded graphite or others graphene derivatives) are, the greater improvements in properties can be obtained. Properties of polymer nanocomposites depend significantly not only on the degree of granularity and uniform dispersion of nanoparticles, but also on the type of polymer matrix and the nature of the nanofiller. In the case of the thermoplastic matrix (such as poly(ethylene terephthalate) (PET) and poly(trimethylene terephthalate) (PTT)), nanofiller may also affect the crystallization rate and degree of crystallinity and the nature of the crystalline phase [36]. Crystallinity is an important field of interest in polymer science and engineering as the crystallinity affects physical properties such as modulus, tensile strength, toughness, hardness, and gas permeability.

Poly(ethylene terephthalate) (PET) is widely used in a range of high barrier applications because of its good mechanical properties and low cost. PET bottles are widely used in fruit juices, drinks, medicines, and food packaging. However, PET material has the poor barrier properties compared with glass and metal containers. Recently, packing industry has been very interested in improvement of barrier properties of PET for additional applications, due to the observed trend to a progressive change towards the use of containers of plastic material. The improvement of PET permeability to oxygen and even carbon dioxide can broad its application to packing materials which are more sensitive to them. Enhanced barrier properties of PET properties can be achieved with the graphene nanoplatelets (GNPs) due to their unique morphology and size. Also graphene oxide possesses an excellent gas barrier without any chemical reduction [37]. Prevoius studies reported that GO layers and poly(ethylenimine) (PEI) layers deposited on a PET film surface PET decreased the oxygen transmittance rate (OTR) and light transmittance, and the electric conductivity increased [38]. Kim et al. [37] reported that the oxygen permeability of the poly(vinyl alcohol) (PVA)/reduced graphene oxide (RGO) $(0.3 \mathrm{wt} \%)$ composite coated film was 17 times lower than that of the pure poly(ethylene terephthalate) (PET) film. Both the diffusivity and the solubility are reduced by dispersing RGO into PVA.
Graphene and graphene oxide and their uses in barrier polymers are broadly disused in literature [37-41]. The platelet size, stacking orientation, and degree of graphene exfoliation in the polymer matrix are governing factors in determining the gas transport [39].

In our earlier work it was established that by using in situ polymerization method it is possible to obtain nanocomposites with highly exfoliated graphene sheets in PET matrix with electrical percolation threshold at $0.05 \mathrm{wt} \%$ loading of expanded graphite [42].

In the present study, up to $0.5 \mathrm{wt} \%$ of GO was introduced in PET matrix. The effect of GO presence in PET matrix on oxygen barrier properties and nonisothermal crystallization behavior of the obtained PET nanocomposites were investigated. The last studies are of great practical importance because the production of PET the production of PET products, including fiber spinning, extrusion, and injection molding, is largely controlled trough nonisothermal crystallization processes. In fact, the interaction between the polymer and the functionalized groups on the surface of graphene sheets can alter the thermal properties of the nanocomposites.

\section{Experimental}

2.1. Materials. Poly(ethylene terephthalate) (PET) has been synthesized by using the following chemicals: dimethyl terephthalate (DMT) (Sigma-Aldrich); ethanediol (ED) (Sigma-Aldrich), zinc acetate (ester exchange catalyst) $\mathrm{Zn}\left(\mathrm{CH}_{3} \mathrm{COO}\right)_{2}$ (Sigma-Aldrich); antimony trioxide-polycondensation catalyst: $\mathrm{Sb}_{2} \mathrm{O}_{3}$ (Sigma-Aldrich); thermal stabilizer Irganox 1010 (Ciba-Geigy, Switzerland).

Graphene oxide (GO) with average particle size of $5 \mu \mathrm{m}$ was provided by Polymer Institute of Slovak Academy of Sciences, where the natural graphite was converted to expanded graphite through chemical oxidation in the presence of concentrated $\mathrm{H}_{2} \mathrm{SO}_{4}$ and $\mathrm{HNO}_{3}$ acids reported in [43]. C1s XPS spectra of GO are as follows: $\mathrm{sp}^{2}-\mathrm{C}$ : $60.00 \%$; $\mathrm{sp}^{3}-\mathrm{C}$ : $12.92 \%$; C-O: 9.22\%; C=O: 6.42\%; COO: $2.95 \% ; \pi-\pi: 8.49 \%$. O1s XPS spectra of $\mathrm{GO}$ are as follows: $\mathrm{C}=\mathrm{O}: 37.45 \%, \mathrm{C}-\mathrm{O}: 52.49 \%$, $\mathrm{Na}-\mathrm{O}: 5.86 \%$, and $\mathrm{SiO}_{2}: 4.20 \%$. Before adding nanofillers to the reaction mixture, they were combined with ethanediol in order to split agglomerates and to improve further exfoliation.

2.2. Preparation of PET/GO Nanocomposite. PET/GO nanocomposites were prepared by in situ polymerization in the steel reactor (Autoclave Engineers, USA) with capacity of $1000 \mathrm{~cm}^{3}$. The process was conducted in two stages and followed the same procedure as described in our previous publications [42, 44, 45]. Before polymerization, the desired amount of GO was dispersed in ca. $250-300 \mathrm{~mL}$ of ED by using for $15 \mathrm{~min}$ intensive mixing with high-speed stirrer (Ultra-Turax T25) and then through ultrasonication for 15 min using sonicator (Homogenizer HD 2200, Sonoplus, with frequency of $20 \mathrm{kHz}$ and $75 \%$ of power $200 \mathrm{~W}$ ). Additionally, to improve the dispersion/exfoliation of GO in ED an ultrapower lower sonic bath (BANDELIN, Sonorex digitec, 
with frequency of $35 \mathrm{kHz}$ and power $140 \mathrm{~W}$ ) was applied for 20 hours.

2.3. Characterization Techniques. The inherent viscosity $[\eta]$ of the polymers was determined at $30^{\circ} \mathrm{C}$ using an Ubbelohde viscometer (with capillary $I_{c}, K=0.03294$ ), as described elsewhere [42, 45-47]. The polymer solution had a concentration of $0.5 \mathrm{~g} / \mathrm{dL}$ in mixture phenol/1,1,2,2-tetrachloroethane ( $60 / 40$ by weight). The polymer nanocomposite solution was filtered through $0.2 \mu \mathrm{m}$ pore size polytetrafluoroethylene (PTFE) filter (Whatman; membrane type TE 35) to ensure that the intrinsic viscosity is not affected by present GO. After filtration, the polymer was precipitated and redissolved. The values of average viscosity molar mass of PET homopolymer was calculated according to the Mark-Houwink equation $[\eta]=3.72 \times 10^{-4} \cdot M^{0.73}[48]$.

The melt volume rate (MVR) was measured using a melt indexer (CEAST, Italy) as melt flow in $\mathrm{cm}^{3}$ per $10 \mathrm{~min}$, at temperature of $280^{\circ} \mathrm{C}$ and at orifice diameter $1.050 \mathrm{~mm}$ and under $2.160 \mathrm{~kg}$ load, according to ISO 1133 specification.

The structure of nanocomposites was observed by transmission electron microscopy (TEM) analysis, which was carried out by a JEOL JEM-1200 Electron Microscope using an acceleration voltage of $80 \mathrm{kV}$. The TEM samples were thinly sliced $(\sim 100 \mathrm{~nm})$ using Reichert Ultracut R ultramicrotome. The thin slice obtained was collected onto a 300 mesh copper grid.

Oxygen permeability was measured using a Mocon-OxTran 2/10 instrument. Oxygen permeability was performed using $5 \mathrm{~cm}^{2}$ samples of investigated polymer films in accordance with ASTM D3985-05 and ISO 15105-2 Standards. All film samples were additionally conditioned for $3 \mathrm{~h}$ in the test chamber of OX-Tran apparatus in test parameters $\left(23^{\circ} \mathrm{C}\right.$ and $0 \%$ humidity rate $\mathrm{RH}$ ). The measurement was automatically terminated when apparatus obtained stable subsequent results. Samples were dried in vacuum at $80^{\circ} \mathrm{C}$ for $24 \mathrm{~h}$, compression-moulded, and quenched into amorphous films. The temperature of the press was $255^{\circ} \mathrm{C}$ and pressure of $15 \mathrm{bar}$. Films with comparable thinness $(330 \mu \mathrm{m})$ were prepared.

XRD diffraction patterns were recorded using a PANalytical X'Pert PRO diffractometer powered by a Philips PW3040/60 X-ray generator and fitted with an X'Celerator detector. The X-ray source (CuKa radiation, wavelength $\lambda=$ $1.5418 \AA$ ) was generated using an applied voltage of $40 \mathrm{kV}$ and a filament current of $35 \mathrm{~mA}$. The data were collected and recorded in the $2 \theta$ range $4-40$ with a step of 0.02 .

The nonisothermal crystallization behaviours of samples were investigated using a differential scanning calorimetry (DSC, TA Instruments Q-1000). The samples were heated from room temperature to $270^{\circ} \mathrm{C}$ at heating rate $10^{\circ} \mathrm{C} / \mathrm{min}$ and maintained for $3 \mathrm{~min}$ in the DSC cell to destroy any nuclei that might act as seed crystals. The samples were then cooled to $20^{\circ} \mathrm{C}$ at constant rate of 3,5 , and $10^{\circ} \mathrm{C} / \mathrm{min}$, respectively. All the DSC measurements were carried out in nitrogen atmosphere, and the weight of each sample was about $10 \mathrm{mg}$. The enthalpy of crystallization $\left(\Delta H_{c}\right)$ was determined from the areas of the crystallization peaks. The degree of crystallinity $\left(x_{c}\right.$, mass fraction) of the samples was calculated using the equation

$$
x_{c}=\frac{\Delta H_{c}}{\Delta H^{0}(1-w)},
$$

where $\Delta H^{0}(140 \mathrm{~J} / \mathrm{g})$ [44] is the enthalpy of melting for $100 \%$ crystalline PET, $\Delta H_{c}$ is the enthalpy of crystallization of the sample, and $w$ is the content of GO.

Small angle X-ray scattering (SAXS) measurements were performed at beam line A2 at HASYLAB (DESY, Hamburg). The wavelength of the X-ray beam was $\lambda=0.15 \mathrm{~nm}$. Scattering patterns were collected by a two-dimensional MAR-CCD-165 detector placed at a distance of $2443 \mathrm{~mm}$ from the sample. The scattering-vectors were calibrated using a dray rat-tail tendon protein. The specimens ( $25 \mathrm{mg}$ ) were mounted in Mettler hot stage and encased between aluminium-foil windows and were heated and cooled at heating rates of $5^{\circ} \mathrm{C} / \mathrm{min}$ over a temperature range of $25-275^{\circ} \mathrm{C}$. During cooling from the melt, data was collected with time scanning 60 and accumulation time $20 \mathrm{~s}$. For SAXS data analysis, a computer program SAXSDAT [49] was used. Subsequently the linear correlation function $\mathrm{CF}(x)$ (2) Fourier-transformed from the corresponding one-dimensional SAXS data $I(s)$ measured is calculated in this work following procedures described in [49]:

$$
\mathrm{CF}(x)=\frac{1}{\mathrm{Q}} \int_{0}^{\infty} I(s) s^{2} \cos (2 \pi s x) d s .
$$

The parameter $Q$ in (2) is a measure of the scattering power of the system:

$$
Q=\int_{0}^{\infty} I(s) s^{2} d s=K \alpha_{s}\left(\rho_{c}-\rho_{a}\right)^{2} \varphi_{L}\left(1-\varphi_{L}\right),
$$

where $\rho_{c}$ is the electron density of the lamellar crystals, $\rho_{a}$ is the electron density of the amorphous material between adjacent lamellae, $\alpha_{s}$ is the volume fraction of the lamellar crystals in the irradiated sample volume, and $K$ is the a constant depending on the experimental conditions. From the correlation function, we estimate long period $L$ (the first maximum) and the linear crystallinity $\varphi_{L}$ using the equation [49-51]

$$
\varphi_{L}\left(1-\varphi_{L}\right)=\frac{P}{L},
$$

where $P$ is the position of the first intercept of the correlation function with the $x$-axis. The thickness of the crystalline $\left(l_{c}\right)$ and amorphous $\left(l_{a}\right)$ layers in the stacks was calculated according to

$$
\begin{aligned}
& l_{l}=\varphi_{L} L, \\
& l_{a}=\left(1-\varphi_{L}\right) L .
\end{aligned}
$$

The relationship between volume fraction of crystallinity and linear crystallinity is expressed as $x_{v}=\alpha_{s} \varphi_{L}$, where $\alpha_{s}$ is the fraction of the total volume of the sample occupied by stacks of lamellae [51]. Using the densities of the crystalline $\left(d_{c}=1.445 \mathrm{~g} / \mathrm{cm}^{3}\right)$ and amorphous $\left(d_{a}=1.331 \mathrm{~g} / \mathrm{cm}^{3}\right)$ phases 
TABLE 1: Physical properties of neat PET and PET/GO nanocomposites.

\begin{tabular}{lccc}
\hline Sample & $\begin{array}{c}{[\eta]} \\
\mathrm{dL} / \mathrm{g}\end{array}$ & $\begin{array}{c}M_{v} \times 10^{4} \\
\mathrm{~g} / \mathrm{mol}\end{array}$ & $\begin{array}{c}\mathrm{MVR} \\
\mathrm{cm}^{3} / 10 \mathrm{~min}\end{array}$ \\
\hline PET & 0.536 & 2.124 & $72.8 \pm 1.9$ \\
PET/0.1GO & 0.532 & 2.100 & $72.5 \pm 1.8$ \\
PET/0.3GO & 0.529 & 2.090 & $71.9 \pm 2.5$ \\
PET/0.5GO & 0.499 & 1.927 & $72.8 \pm 1.4$ \\
\hline
\end{tabular}

[ $\eta$ ]: intrinsic viscosity; $M_{v}$ : average viscosity molecular weight; MVR: melt volume rate at $280^{\circ} \mathrm{C}$.

for PET [52], the volume fraction crystallinity $\left(x_{v}=\varphi_{L}\right)$ was transformed into mass fraction of crystallinity $x_{c, m}$ according to Swam equation [53]:

$$
x_{c, m}=\left[1+\frac{d_{a}}{d_{c}}\left(\frac{1-x_{v}}{x_{v}}\right)\right]^{-1} .
$$

\section{Results and Discussion}

3.1. Characterization of the PET/GO Nanocomposites. PET nanocomposites with low loading of graphene oxide (GO) were synthesized by in situ polymerization of monomers in the presence of GO sheets. Ultrasonication graphite oxide in monomer (ED) before synthesis and then polymerization was found to be an effective way to obtain PET nanocomposites with highly exfoliated GO into while maintaining a very high aspect. Additionally, for comparison purposes, unmodified PET was synthesized and characterized in the same manner as the nanocomposite. The characteristics of the obtained nanocomposites are presented in Table 1. The intrinsic viscosity of neat PET was $0.536 \mathrm{dL} / \mathrm{g}$.

The presence of the GO in the polymerization mixture affected the reaction, leading to the slightly decrease of intrinsic viscosity. As shown in Table 1, the intrinsic viscosity decreased with the addition of GO to 0.499 . The PET matrix in synthesized nanocomposites have high molecular weight, which is ranged between 21000 and $19200 \mathrm{~g} / \mathrm{mol}$ and is close to the value for neat PET. The comparable value of melt volume rate for neat PET and PET/GO nanocomposites was due to the polymer-functionalized graphene sheets interactions.

The dispersion and exfoliation of functionalized graphene sheets (GO) in PET matrix were investigated using TEM analysis and representative images for composite with loading of 0.3 and $0.5 \mathrm{wt} \%$ are shown in Figure 1.

TEM images of the PET/GO nanocomposites demonstrate that the highly exfoliated graphene oxide nanoplatelets were rather uniformly dispersed in PET matrix. The presence of more or less transparent and graphene nanoplatelets conforms with high degree of exfoliation, although predominance of folded multilayer graphene and some small aggregates on the nanoscopic scale was observed. This was due to the extremely high specific area of GO and the strong particlematrix interactions that take place. The fact that the graphene oxide flakes remain well-exfoliated and highly dispersed within PET matrix suggests these composites to potentially display gas barrier property improvement.
TABLE 2: Oxygen permeability of PET/GO nanocomposite films.

\begin{tabular}{lccc}
\hline Sample & $\begin{array}{c}\text { GO } \\
\text { wt } \%\end{array}$ & $\begin{array}{c}\text { Thickness } \\
\mu \mathrm{m}\end{array}$ & $\begin{array}{c}\mathrm{O}_{2} \text { transmission rate }^{\mathrm{a}} \\
\mathrm{cm}^{3} / \mathrm{m}^{2} 24 \mathrm{~h}\end{array}$ \\
\hline PET & - & 320 & $48.6 \pm 3.7$ \\
PET/0.1GO & 0.1 & 326 & $23.7 \pm 2.3$ \\
PET/0.3GO & 0.3 & 322 & $18.6 \pm 1.6$ \\
PET/0.5GO & 0.5 & 320 & $14.6 \pm 2.1$ \\
\hline
\end{tabular}

${ }^{a}$ Measured at $23^{\circ} \mathrm{C}$ and $0 \%$ relative humidity.

3.2. Oxygen Permeability of PET/GO Nanocomposites. Graphene nanoplatelets are believed to increase gas barrier properties in nanocomposites. The tortuous path being created by the graphene particles in PET nanocomposites can retards the diffusion of the gas molecules through the PET matrix region. The influence of functionalized graphene (GO) content on the barrier performance to oxygen was studied by investigating oxygen transmission rate of PET/GO nanocomposites.

Gas barrier properties of PET films can be influenced by sample crystallinity and thickness [54]. In order to avoid crystallinity effect on oxygen barrier properties of PET/GO nanocomposites the amorphous films with comparable thickness were prepared.

Figure 2 shows X-ray diffraction patterns of GO, neat PET, and PET/GO composite films. The X-ray patterns for PET and PET/GO nanocomposite films have a broad amorphous halo confirming that prepared films were amorphous. The $\mathrm{X}$-ray diffraction patterns for $\mathrm{GO}$ give peaks at $2 \theta=12.5^{\circ}$ and $2 \theta=26.3^{\circ}$. The first peak corresponds to an interlayer spacing of $0.71 \mathrm{~nm}$ (002) indicating the presence of oxygen functional group. The second peak corresponds to (002) plane of graphite with interlayer spacing of $0.34 \mathrm{~nm}$. The presence of any GO peaks in the XRD spectra of PET/GO nanocomposites can suggests that GO was well exfoliated and homogenous dispersed in the PET matrix. On the other hand, GO content in PET matrix can be too low to observe these peaks on X-ray diffraction spectra of PET/GO nanocomposite films.

The oxygen barrier properties through neat PET and PET/GO composite films with comparable thickness are listed in Table 2. The obtained results of oxygen transmission rate (OTR) for amorphous PET films are comparable with literature data [54]. As expected, the permeability of $\mathrm{O}_{2}$ through the PET/GO nanocomposite films was found considerably reduced at low loading of GO. The improvement of $\mathrm{O}_{2}$ permeability for PET nanocomposite films over the neat PET is approximately factors of 2-3.3.

Based on many studies of gas barrier properties of polymer-layered silicate nanocomposites, it was established that enhancements in gas barrier properties depend on factors such as the relative orientation of the nanofiller sheets in the polymer matrix and the state of aggregation and dispersion in polymer matrix, that is, intercalated, exfoliated, or mixed morphology [55]. For PET nanocomposites containing graphene nanoplatelets the mechanism of gas barrier properties enhancement can be influenced by many factors similar to polymer-layered silicate nanocomposites, for which the level of exfoliation of silicate layers is a critical 


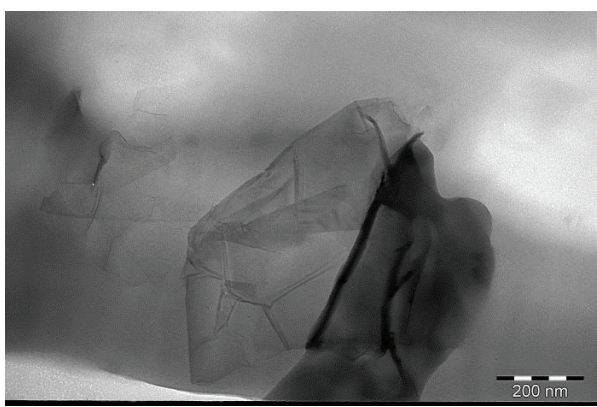

(a)

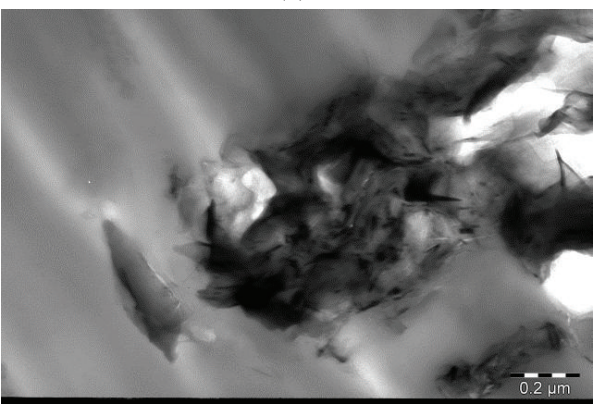

(c)

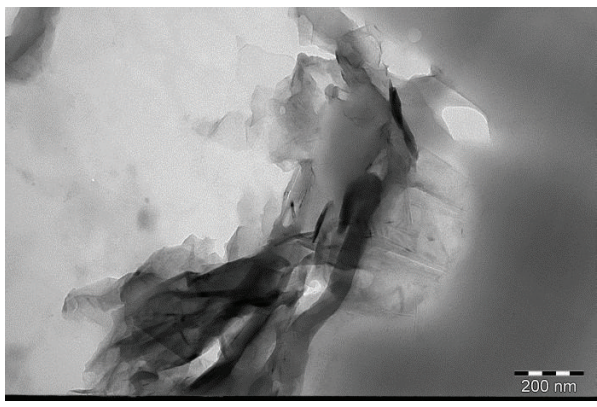

(e)

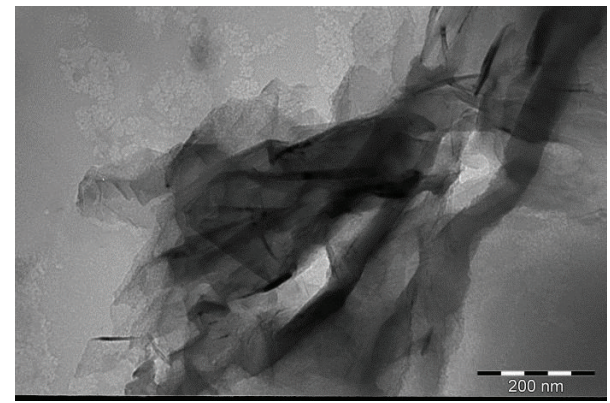

(b)

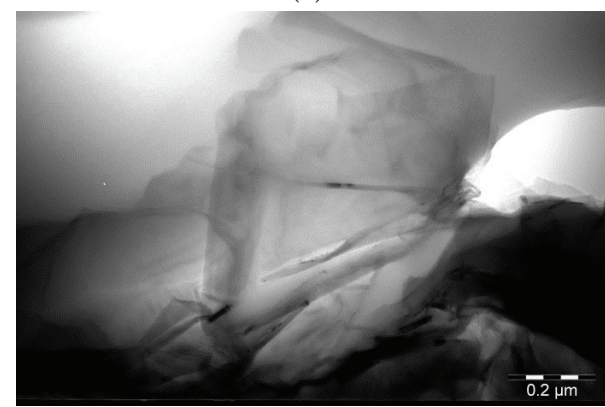

(d)

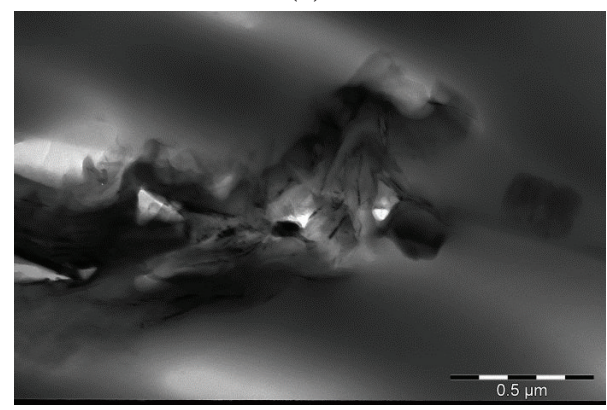

(f)

FIGURE 1: TEM images of PET/GO nanocomposite with $0.3 \mathrm{wt} \%$ (a-b) and $0.5 \mathrm{wt} \%$ (c-f) of GO. Image magnification: (a) $150 \mathrm{k}$, (b) $200 \mathrm{k}$, (c) $50 \mathrm{k},(\mathrm{d}) 150 \mathrm{k},(\mathrm{e}) 120 \mathrm{k}$, and (f) $100 \mathrm{k}$.

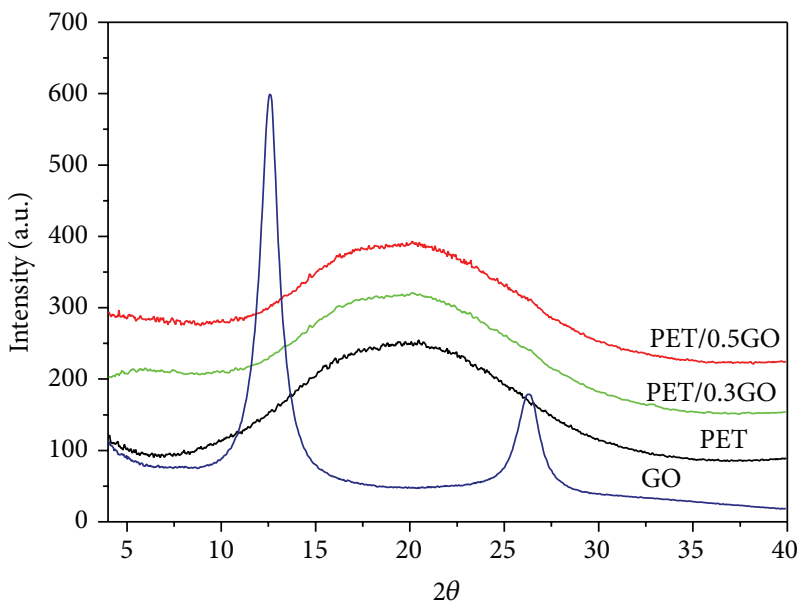

FIGURE 2: XRD diffractograms for GO, neat PET, and PET/GO nanocomposite films.

factor in determining the maximum performance of polymer silicate nanocomposites for barrier applications [56].
3.3. Effect of GO on Crystallization of PET Nanocomposites. The effect of graphene oxide nanoplatelets on the nonisothermal crystallization of PET was investigated using DSC. Figure 3 shows the DSC cooling curves obtained at different cooling rates. Additionally, temperature-resolved SAXS studies of morphological changes in melt-crystallized PET and $\mathrm{PET} / \mathrm{GO}$ composite with the highest concentration of GO $(0.5 \mathrm{wt} \%)$ were carried out.

The values of the nonisothermal crystallization onset temperatures $\left(T_{c, \text { on }}\right)$, crystallization peak temperatures $\left(T_{c}\right)$, and the crystallization enthalpies of all the samples under different cooling rates $\left(3,5\right.$, and $\left.10^{\circ} \mathrm{C} / \mathrm{min}\right)$ are presented in Table 3. For all samples, the crystallization onset temperature and crystallization peak temperature decrease as the cooling rate increases. Compared with neat PET, it is observed that at given cooling rate, the onset and peak crystallization temperatures of the PET/GO nanocomposites was increased due to the presence of GO. It can be also seen that the width of crystallization peak for nanocomposites was less than for neat PET. The value of $\left(T_{c, \text { on }}-T_{c}\right)$ reflects the overall crystallization rate of the sample; the lower value of the 


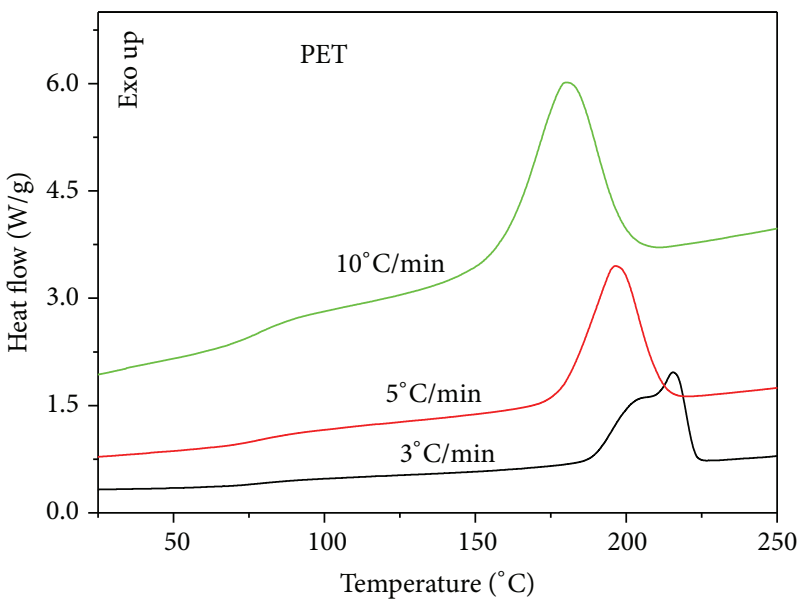

(a)

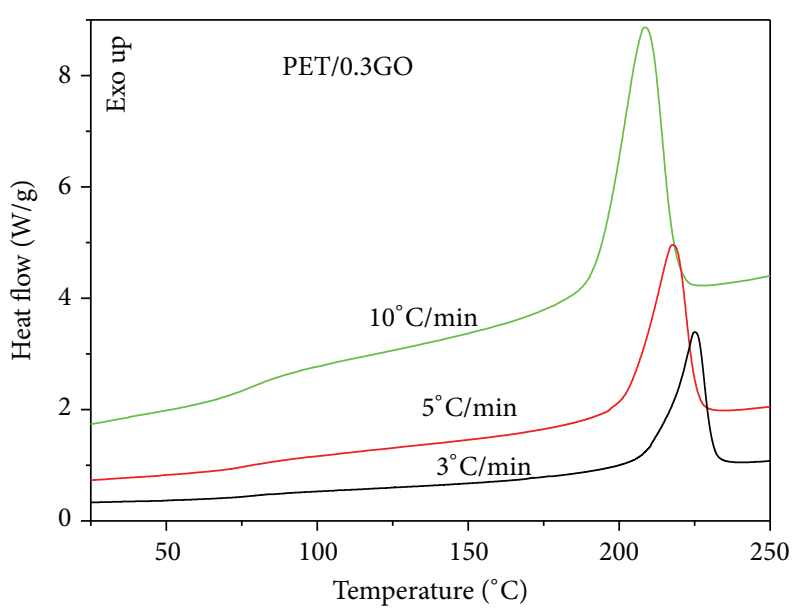

(c)

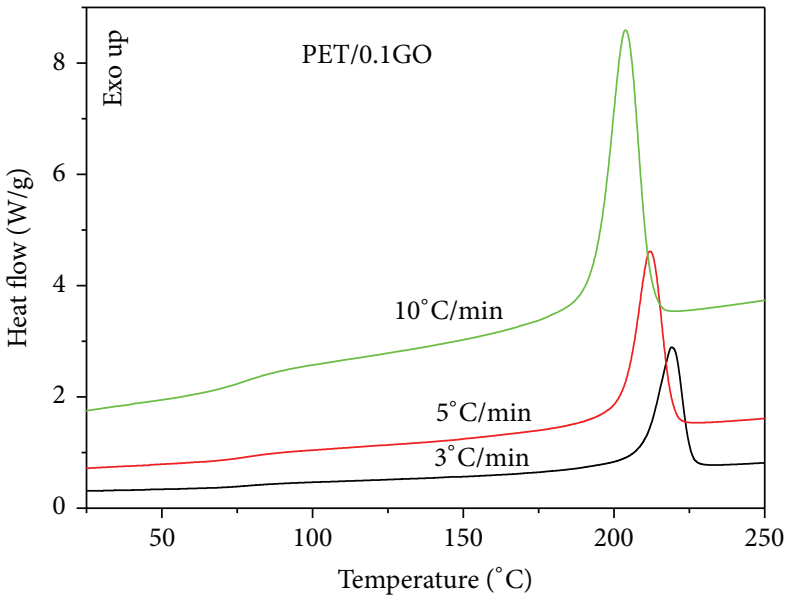

(b)

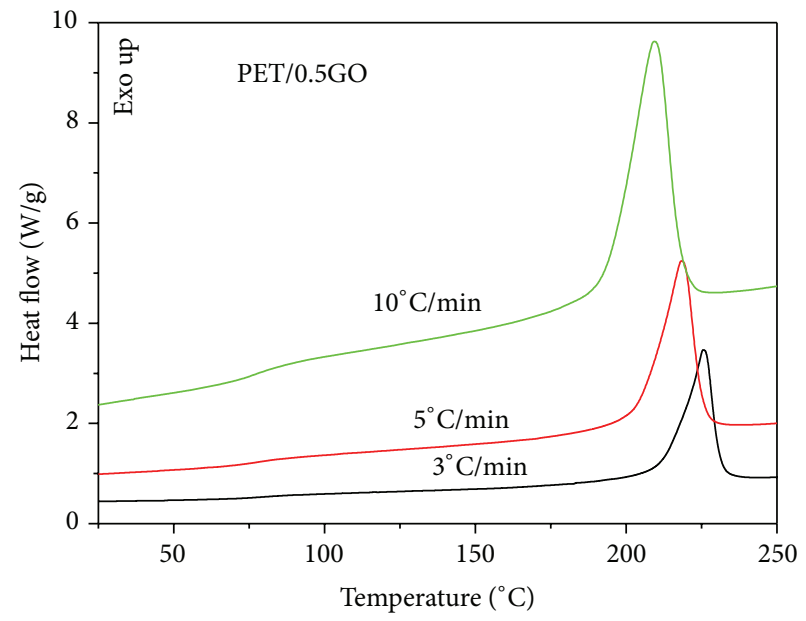

(d)

FIGURE 3: DSC thermograms of neat PET (a) and PET/GO nanocomposites with 0.1 (b), 0.3 (c), and 0.5 (d) wt\% of GO at different cooling rates.

TABLE 3: DSC data obtained from the cooling runs for PET/GO nanocomposites.

\begin{tabular}{|c|c|c|c|c|c|c|}
\hline Sample & $\begin{array}{l}\text { Scan rate } \\
{ }^{\circ} \mathrm{C} / \mathrm{min}\end{array}$ & $\begin{array}{c}T_{c, \text { on }} \\
{ }^{\circ} \mathrm{C}\end{array}$ & $\begin{array}{l}T_{c} \\
{ }^{\circ} \mathrm{C}\end{array}$ & $\begin{array}{c}T_{c, \text { on }}-T_{c} \\
{ }^{\circ} \mathrm{C}\end{array}$ & $\begin{array}{c}\Delta H_{c} \\
\mathrm{~J} / \mathrm{g}\end{array}$ & $x_{c}$ \\
\hline \multirow{3}{*}{ PET } & 3 & 222 & 215 & 7 & 52.9 & 0.378 \\
\hline & 5 & 211 & 196 & 15 & 47.7 & 0.341 \\
\hline & 10 & 200 & 180 & 20 & 42.7 & 0.305 \\
\hline \multirow{3}{*}{$\mathrm{PET} / 0.1 \mathrm{GO}$} & 3 & 225 & 219 & 6 & 51.4 & 0.367 \\
\hline & 5 & 219 & 212 & 7 & 47.8 & 0.342 \\
\hline & 10 & 212 & 203 & 9 & 43.2 & 0.309 \\
\hline \multirow{3}{*}{$\mathrm{PET} / 0.3 \mathrm{GO}$} & 3 & 231 & 225 & 6 & 63.2 & 0.453 \\
\hline & 5 & 225 & 217 & 8 & 56.2 & 0.403 \\
\hline & 10 & 218 & 208 & 10 & 51.5 & 0.369 \\
\hline \multirow{3}{*}{$\mathrm{PET} / 0.5 \mathrm{GO}$} & 3 & 231 & 225 & 6 & 63.6 & 0.456 \\
\hline & 5 & 225 & 218 & 7 & 57.9 & 0.416 \\
\hline & 10 & 218 & 209 & 9 & 52.5 & 0.377 \\
\hline
\end{tabular}

$T_{c, \text { on }}, T_{c}$ : onset and peak crystallization temperature, $\Delta H_{c}$ : enthalpy of crystallization, and $x_{c}$ : mass fraction of crystallinity. 


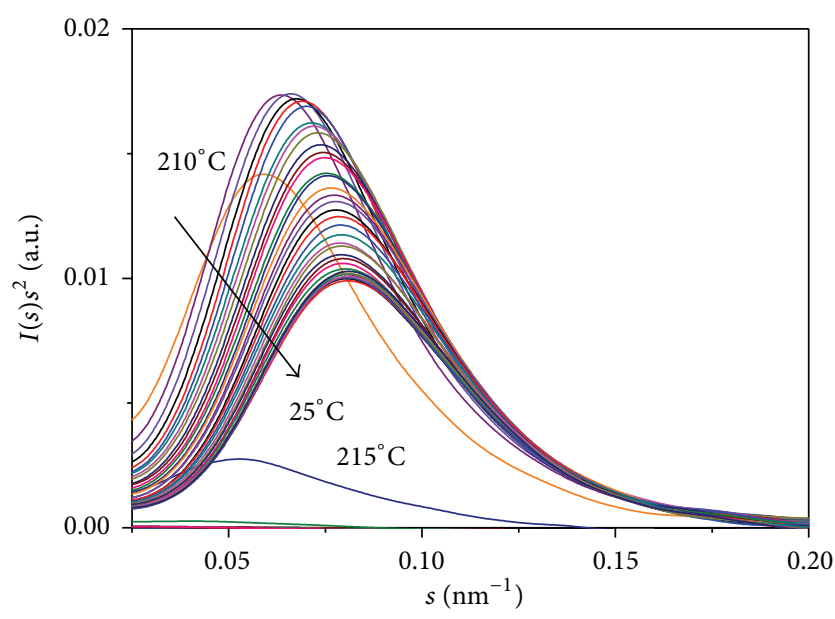

(a)

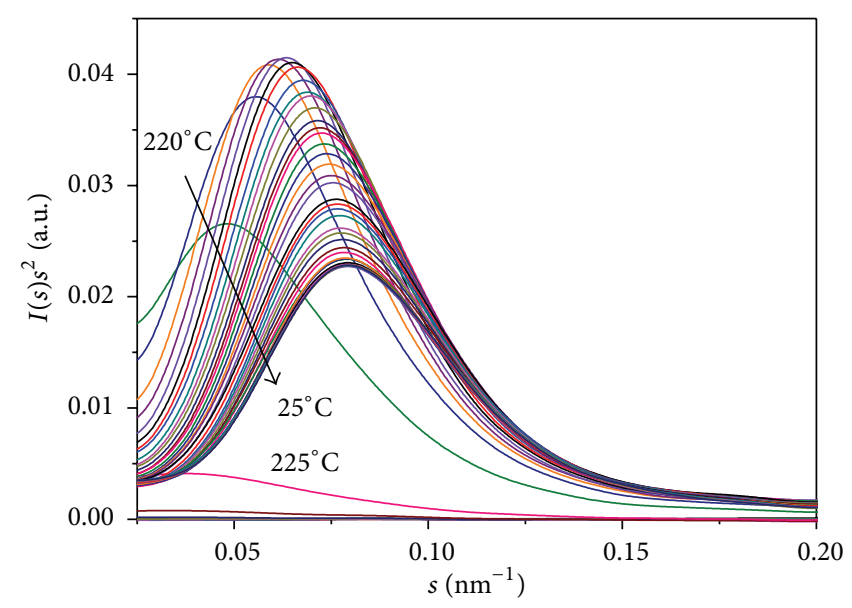

(b)

FIGURE 4: The evolution of the Lorentz corrected SAXS patterns (after background correction) during crystallization of (a) neat PET and (b) PET/0.5GO nanocomposite.

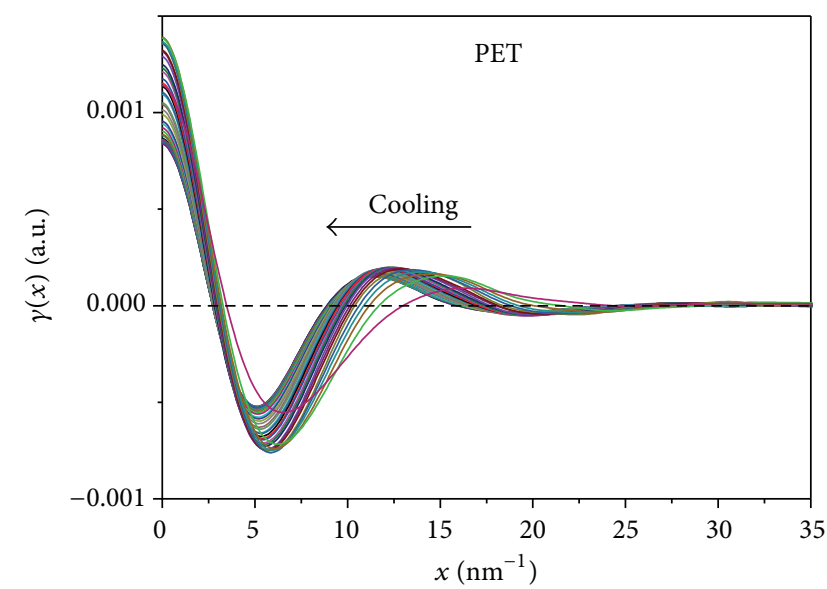

(a)

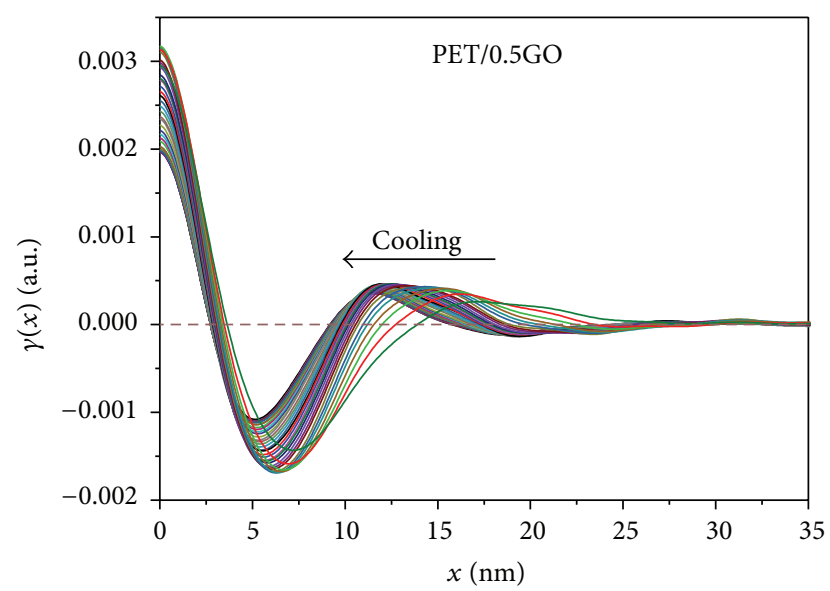

(b)

FIGURE 5: One-dimensional correlation function for neat PET (a) and PET/0.5GO nanocomposite (b) during cooling at $5^{\circ} \mathrm{C} / \mathrm{min}$ form the melt.

$\left(T_{c, \text { on }}-T_{c}\right)$ for nanocomposites especially at higher cooling rates (Table 3 ) indicates the higher overall crystallization rate. Moreover, the nonisothermally crystallized PET composites with 0.3 and $0.5 \mathrm{wt} \%$ of GO have higher degree of crystallinity than neat PET. These can indicate the efficiency of graphene oxide nanoplatelets at low loading as nucleation agents for crystallization of PET.

Effect of the presence of GO in PET matrix on the evolution of the lamellar nanostructure was monitored by SAXS during nonisothermal crystallization from the melt. The correlation function $\gamma(x)$ has been applied to follow the changes of the nanostructure of PET/GO composite and neat PET during crystallization from the melt. Figure 4 displays the evolution of SAXS patterns for neat PET and nanocomposite (PET/0.5GO) during cooling. According to procedure reported in [49-51] analysis of the $\gamma(x)$ (Figure 5) allows to determine: $L, l_{c}, l_{a}$, and crystallinity within the lamellar stacks $\left(\varphi_{L}\right)$.
Figure 6 summarizes the results of the nanostructure studies during melt crystallization of neat PET and nanocomposite with loading of $0.5 \mathrm{wt} \%$ of GO. These data indicate that the average values of lamellar thickness accompanied by the decrease of the amorphous layer $l_{a}$ decreases with decreasing temperature and consistent with previous data for other crystalline polymers and their nanocomposites [57-59]. The observed in the higher-temperature region sharp decrease of the average value of $l_{a}$ could be connected with the sequential formation of either new crystal lamellae or lamellar stacks or both in the interlamellar amorphous regions $[58,59]$.

Finally, unfilled PET and nanocomposite showed almost the similar values of the long period $(L=11.4 \mathrm{~nm}$ for neat PET and $L=11.5 \mathrm{~nm}$ for PET/0.5GO, Table 4). Nanocomposite has comparable thickness of crystalline lamellae (Table 4) as neat PET. Slightly higher value of $l_{c}$ for nanocomposite in comparison to unfilled PET was observed. The obtained volume and mass fraction crystallinity for 
TABLE 4: Parameters of nanostructure determined from correlation function for neat PET and PET/0.5GO nanocomposite.

\begin{tabular}{lcccccc}
\hline Sample & $L[\mathrm{~nm}]$ & $l_{c}[\mathrm{~nm}]$ & $l_{a}[\mathrm{~nm}]$ & $E[\mathrm{~nm}]$ & $\varphi_{L}$ & $x_{c, m}$ \\
\hline PET & 11.40 & 4.412 & 6.988 & 2.103 & 0.387 & 0.406 \\
PET/0.5GO & 11.51 & 4.627 & 6.883 & 1.969 & 0.402 & 0.422 \\
\hline
\end{tabular}

$L$ : long period; $l_{c}$ : thickness of crystalline lamellae; $l_{a}$ : thickness of amorphous layer; $E$ : thickness of transition layer; $\varphi_{c}$ : volume fraction of crystallinity; $x_{c, m}$ : mass fraction of crystallinity determined from (6).

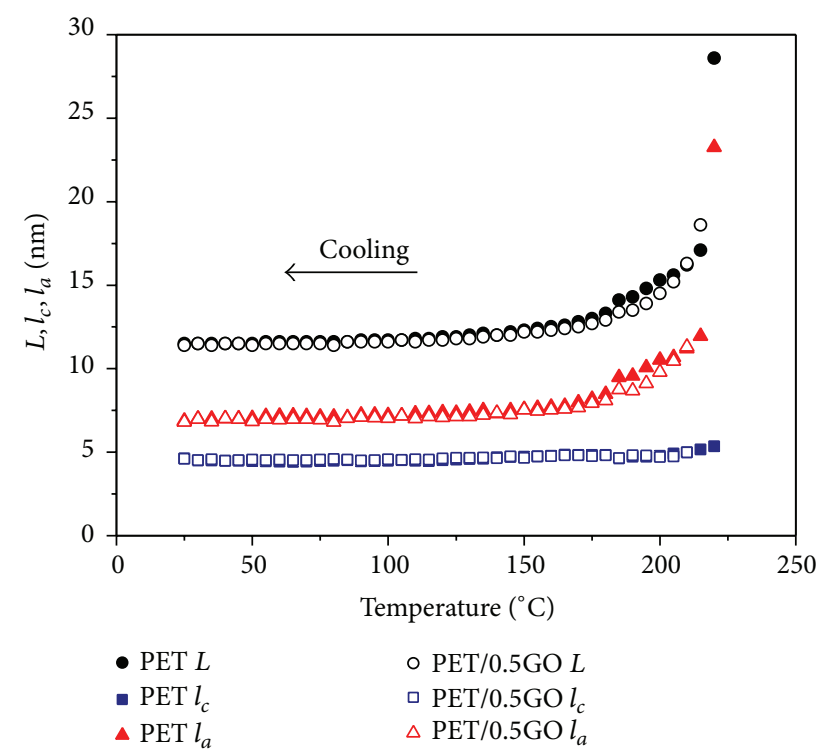

Figure 6: Changes of long period $(L)$, thickness of crystalline, and amorphous layer $\left(l_{c}, l_{a}\right)$ calculated from the one-dimensional correlation function for neat PET and PET/0.5GO nanocomposite during crystallization form the melt.

nanocomposite $(0.402$ and 0.422$)$ are slightly higher than for neat PET (0.387 and 0.406).

The observed difference between values of mass fraction crystallinity determined by DSC (Table 3 ) and SAXS (Table 4) can be explained by different sample size, differences in thermal history, and the different selectivity of the method. Such differences can be excluded only by the simultaneous measurements with different techniques at the same sample volume, which reflect an identical thermophysical history.

\section{Conclusions}

The obtained PET nanocomposites with low loading of GO prepared by in situ polymerization show uniform dispersion of highly exfoliated graphene oxide nanosheets in PET matrix. Study of the oxygen transmission rate through nanocomposite and neat PET films has shown that the high aspect ratio and exfoliated structure of GO in PET matrix improved their oxygen barrier properties. The improvement of oxygen permeability for PET nanocomposite films at $0.3-$ 0.5 wt $\%$ loading of GO over the neat PET is approximately factors of 2-3.3. These improvements of oxygen barrier properties of PET are important from the application point of view in packing industry. For example oxygen sensitive materials can be stored in PET containers and their life time can be elongated. DSC study of nonisothermal crystallization of nanocomposites have shown that the graphene oxide nanosheets displayed a nucleating effect on the PET crystallization due to the increase in the onset and peak crystallization temperature of nanocomposites compared to neat PET. The degree of crystallinity of the nanocomposites containing of 0.3 and $0.5 \mathrm{wt} \%$ of GO are higher than for the neat PET. Analysis of nanostructure parameters obtained from SAXS measurements for PET/0.5GO composite and neat PET have shown that nonisothermally crystallized composite and neat PET have comparable values of long period.

\section{Conflict of Interests}

The authors declare that there is no conflict of interests regarding the publication of this paper.

\section{Acknowledgments}

The authors thank the financial support from MNT ERANET 2012 Project (APGRAPHEL) for sponsoring the study. The experiments performed at A2 in HASYLAB (DESY) were done using the beamtime of the proposal I-20110255EC. Iwona Pawelec would like to acknowledge financial support from West Pomeranian University of Technology (Dean's grant for young scientists).

\section{References}

[1] K. S. Novoselov, A. K. Geim, S. V. Morozov et al., "Electric field effect in atomically thin carbon films," Science, vol. 306, no. 5696, pp. 666-669, 2004.

[2] H. Kim, A. A. Abdala, and C. W. MacOsko, "Graphene/polymer nanocomposites," Macromolecules, vol. 43, no. 16, pp. 65156530, 2010.

[3] K. I. Bolotin, K. J. Sikes, Z. Jiang et al., "Ultrahigh electron mobility in suspended graphene," Solid State Communications, vol. 146, no. 9-10, pp. 351-355, 2008.

[4] K. S. Novoselov, A. K. Geim, S. V. Morozov et al., "Two-dimensional gas of massless Dirac fermions in graphene," Nature, vol. 438, no. 7065, pp. 197-200, 2005.

[5] A. A. Balandin, S. Ghosh, W. Bao et al., "Superior thermal conductivity of single-layer graphene," Nano Letters, vol. 8, no. 3, pp. 902-907, 2008.

[6] A. A. Balandin, "Thermal properties of graphene and nanostructured carbon materials," Nature Materials, vol. 10, no. 8, pp. 569-581, 2011.

[7] J. D. Renteria, D. L. Nika, and A. A. Balandin, "Graphene thermal properties: applications in thermal management and energy storage," Applied Sciences, vol. 4, no. 4, pp. 525-547, 2014.

[8] D. A. Dikin, S. Stankovich, E. J. Zimney et al., "Preparation and characterization of graphene oxide paper," Nature, vol. 448, no. 7152, pp. 457-460, 2007.

[9] C. Lee, X. Wei, J. W. Kysar, and J. Hone, "Measurement of the elastic properties and intrinsic strength of monolayer graphene," Science, vol. 321, no. 5887, pp. 385-388, 2008. 
[10] A. Peigney, C. Laurent, E. Flahaut, R. R. Bacsa, and A. Rousset, "Specific surface area of carbon nanotubes and bundles of carbon nanotubes," Carbon, vol. 39, no. 4, pp. 507-514, 2001.

[11] S. Stankovich, D. A. Dikin, G. H. B. Dommett et al., "Graphenebased composite materials," Nature, vol. 442, no. 7100, pp. 282286, 2006.

[12] H. J. Salavagione, G. Martínez, and M. A. Gómez, "Synthesis of poly(vinyl alcohol)/reduced graphite oxide nanocomposites with improved thermal and electrical properties," Journal of Materials Chemistry, vol. 19, no. 28, pp. 5027-5032, 2009.

[13] T. Ramanathan, A. A. Abdala, S. Stankovich et al., "Functionalized graphene sheets for polymer nanocomposites," Nature Nanotechnology, vol. 3, no. 6, pp. 327-331, 2008.

[14] L. Al-Mashat, K. Shin, K. Kalantar-Zadeh et al., "Graphene/ polyaniline nanocomposite for hydrogen sensing," The Journal of Physical Chemistry C, vol. 114, no. 39, pp. 16168-16173, 2010.

[15] Y. Dan, Y. Lu, N. J. Kybert, Z. Luo, and A. T. C. Johnson, "Intrinsic response of graphene vapor sensors," Nano Letters, vol. 9, no. 4, pp. 1472-1475, 2009.

[16] Y. B. Zhang, Y.-W. Tan, H. L. Stormer, and P. Kim, "Experimental observation of the quantum Hall effect and Berry's phase in graphene," Nature, vol. 438, no. 7065, pp. 201-204, 2005.

[17] S. Park and R. S. Ruoff, "Chemical methods for the production of graphenes," Nature nanotechnology, vol. 4, no. 4, pp. 217-224, 2009.

[18] X. Wang, H. You, F. Liu et al., "Large-scale synthesis of fewlayered graphene using CVD," Chemical Vapor Deposition, vol. 15 , no. 1-3, pp. 53-56, 2009.

[19] Y. Wang, X. Chen, Y. Zhong, F. Zhu, and K. P. Loh, "Large area, continuous, few-layered graphene as anodes in organic photovoltaic devices," Applied Physics Letters, vol. 95, no. 6, Article ID 063302, 2009.

[20] S. Karmakar, N. V. Kulkarni, A. B. Nawale et al., "A novel approach towards selective bulk synthesis of few-layer graphenes in an electric arc," Journal of Physics D: Applied Physics, vol. 42, no. 11, Article ID 115201, 2009.

[21] W. A. de Heer, C. Berger, X. Wu et al., "Epitaxial graphene," Solid State Communications, vol. 143, no. 1-2, pp. 92-100, 2007.

[22] P. W. Sutter, J.-I. Flege, and E. A. Sutter, "Epitaxial graphene on ruthenium," Nature Materials, vol. 7, no. 5, pp. 406-411, 2008.

[23] Th. Seyller, A. Bostwick, K. V. Emtsev et al., "Epitaxial graphene: a new material," Physica Status Solidi (B), vol. 245, no. 7, pp. 1436-1446, 2008.

[24] Y. Carissan and W. Klopper, "Growing graphene sheets from reactions with methyl radicals: a quantum chemical study," ChemPhysChem, vol. 7, no. 8, pp. 1770-1778, 2006.

[25] C.-D. Kim, B.-K. Min, and W.-S. Jung, "Preparation of graphene sheets by the reduction of carbon monoxide," Carbon, vol. 47, no. 6, pp. 1610-1612, 2009.

[26] A. Hirsch, "Unzipping carbon nanotubes: a peeling method for the formation of graphene nanoribbons," Angewandte Chemie, vol. 48, no. 36, pp. 6594-6596, 2009.

[27] L. Jiao, L. Zhang, X. Wang, G. Diankov, and H. Dai, "Narrow graphene nanoribbons from carbon nanotubes," Nature, vol. 458, no. 7240, pp. 877-880, 2009.

[28] K. A. Worsley, P. Ramesh, S. K. Mandal, S. Niyogi, M. E. Itkis, and R. C. Haddon, "Soluble graphene derived from graphite fluoride," Chemical Physics Letters, vol. 445, no. 1-3, pp. 51-56, 2007.

[29] I. Janowska, F. Vigneron, D. Bégin et al., "Mechanical thinning to make few-layer graphene from pencil lead," Carbon, vol. 50, no. 8, pp. 3106-3110, 2012.
[30] W. S. Hummers Jr. and R. E. Offeman, "Preparation of graphitic oxide," Journal of the American Chemical Society, vol. 80, no. 6, p. 1339, 1958.

[31] D. R. Dreyer, S. Park, C. W. Bielawski, and R. S. Ruoff, "The chemistry of graphene oxide," Chemical Society Reviews, vol. 39, no. 1, pp. 228-240, 2010.

[32] W. Gao, L. B. Alemany, L. Ci, and P. M. Ajayan, "New insights into the structure and reduction of graphite oxide," Nature Chemistry, vol. 1, no. 5, pp. 403-408, 2009.

[33] A. B. Bourlinos, D. Gournis, D. Petridis, T. Szabó, A. Szeri, and I. Dékány, "Graphite oxide: chemical reduction to graphite and surface modification with primary aliphatic amines and amino acids," Langmuir, vol. 19, no. 15, pp. 6050-6055, 2003.

[34] S. Stankovich, D. A. Dikin, R. D. Piner et al., "Synthesis of graphene-based nanosheets via chemical reduction of exfoliated graphite oxide," Carbon, vol. 45, no. 7, pp. 1558-1565, 2007.

[35] A. K. Geim and K. S. Novoselov, “The rise of graphene," Nature Materials, vol. 6, no. 3, pp. 183-191, 2007.

[36] Y. Wang, C. Shen, and J. Chen, "Nonisothermal cold crystallization kinetics of poly(ethylene terephthalate)/clay nanocomposite," Polymer Journal, vol. 35, no. 11, pp. 884-889, 2003.

[37] H. M. Kim, J. K. Lee, and H. S. Lee, "Transparent and high gas barrier films based on poly(vinyl alcohol)/graphene oxide composites," Thin Solid Films, vol. 519, no. 22, pp. 7766-7771, 2011.

[38] L. Yu, Y.-S. Lim, J. H. Han et al., "A graphene oxide oxygen barrier film deposited via a self-assembly coating method," Synthetic Metals, vol. 162, no. 7-8, pp. 710-714, 2012.

[39] B. M. Yoo, H. J. Shin, H. W. Yoon, and H. B. Park, "Graphene and graphene oxide and their uses in barrier polymers," Journal of Applied Polymer Science, vol. 131, no. 1, Article ID 39628, 2014.

[40] Y. Su, V. G. Kravets, S. L. Wong, J. Waters, A. K. Geim, and R. R. Nair, "Impermeable barrier films and protective coatings based on reduced graphene oxide," Nature Communications, vol. 5, article 4843, 2014.

[41] H.-D. Huang, P.-G. Ren, J. Chen, W.-Q. Zhang, X. Ji, and Z.-M. $\mathrm{Li}$, "High barrier graphene oxide nanosheet/poly(vinyl alcohol) nanocomposite films," Journal of Membrane Science, vol. 409410, pp. 156-163, 2012.

[42] S. Paszkiewicz, A. Szymczyk, M. Soccio, J. Mosnáček, T. A. Ezquerra, and Z. Rosłaniec, "Electrical conductivity of poly(ethylene terephthalate)/expanded graphite nanocomposites prepared by in situ polymerization," Journal of Polymer Science, Part B: Polymer Physics, vol. 50, no. 23, pp. 1645-1652, 2012.

[43] Z. Špitalsk, M. Danko, and J. Mosnáček, "Preparation of functionalized graphene sheets," Current Organic Chemistry, vol. 15, no. 8, pp. 1133-1150, 2011.

[44] S. Paszkiewicz, A. Szymczyk, Z. Špitalský, M. Soccio, J. Mosnáček, and Z. Roslaniec, "Morphology and thermal properties of expanded graphite (EG)/poly(ethylene terephthalate) (PET) nanocomposites," Chemik, vol. 66, no. 1, pp. 21-30, 2012.

[45] J. J. Hernández, M. C. García-Gutiérrez, A. Nogales et al., "Influence of preparation procedure on the conductivity and transparency of SWCNT-polymer nanocomposites," Composites Science and Technology, vol. 69, no. 11-12, pp. 1867-1872, 2009.

[46] A. Szymczyk, Z. Roslaniec, M. Zenker et al., "Preparation and characterization of nanocomposites based on $\mathrm{COOH}$ functionalized multi-walled carbon nanotubes and on poly(trimethylene terephthalate)," Express Polymer Letters, vol. 5, no. 11, pp. 977-995, 2011. 
[47] A. Szymczyk, "Structure and properties of new polyester elastomers composed of poly(trimethylene terephthalate) and poly(ethylene oxide)," European Polymer Journal, vol. 45, no. 9, pp. 2653-2664, 2009.

[48] K. A. Anand, U. S. Agarwal, and R. Joseph, "Carbon nanotubesreinforced PET nanocomposite by melt-compounding," Journal of Applied Polymer Science, vol. 104, no. 5, pp. 3090-3095, 2007.

[49] S. Rabiej and M. Rabiej, "Determination of the parameters of lamellar structure of semicrystalline polymers using a computer program SAXSDAT," Polimery, vol. 56, no. 9, pp. 662-670, 2011.

[50] W. Ruland, "Small-angle scattering of two-phase systems: determination and significance of systematic deviations from Porod's law," Journal of Applied Crystallography, vol. 4, no. 1, pp. 70-73, 1971.

[51] B. Goderis, H. Reynares, M. H. J. Koch, and V. B. F. Mathot, "Use of SAXS and linear correlation functions for the determination of the crystallinity and morphology of semi-crystalline polymers. Application to linear polyethylene," Journal of Polymer Science, Part B: Polymer Physics, vol. 37, no. 14, pp. 1715-1738, 1999.

[52] J. B. Brolly, D. I. Bower, and I. M. Ward, "Finite difference modeling of the gas transport process in glassy polymers," Journal of Polymer Science Part B: Polymer Physics, vol. 34, no. 4, pp. 761-768, 1996.

[53] P. R. Swam, "Polyethylene specific volume, crystallinity, and glass transition," Journal of Polymer Science, vol. 42, no. 140, pp. 525-534, 1960.

[54] R. Y. F. Liu, Y. S. Hu, M. R. Hibbs et al., "Improving oxygen barrier properties of poly(ethylene terephthalate) by incorporating isophthalate. I. Effect of orientation," Journal of Applied Polymer Science, vol. 98, no. 4, pp. 1615-1628, 2005.

[55] G. Choudalakis and A. D. Gotsis, "Permeability of polymer/clay nanocomposites: a review," European Polymer Journal, vol. 45, no. 4, pp. 967-984, 2009.

[56] R. K. Bharadwaj, "Modeling the barrier properties of polymerlayered silicate nanocomposites," Macromolecules, vol. 34, no. 26, pp. 9189-9192, 2001.

[57] A. Szymczyk and Z. Roslaniec, "Non-isothermal crystallization of poly(trimethylene terephthalate)/single-walled carbon nanotubes nanocomposites," Polimery, vol. 57, no. 3, pp. 221-227, 2012.

[58] A. Sanz, A. Nogales, T. A. Ezquerra, M. Soccio, A. Munari, and N. Lotti, "Cold crystallization of poly(trimethylene terephthalate) as revealed by simultaneous WAXS, SAXS, and dielectric spectroscopy," Macromolecules, vol. 43, no. 2, pp. 671-679, 2010.

[59] R. Verrna, H. Marand, and B. Hsiao, "Morphological changes during secondary crystallization and subsequent melting in poly(ether ether ketone) as studied by real time small angle Xray scattering," Macromolecules, vol. 29, no. 24, pp. 7767-7775, 1996. 

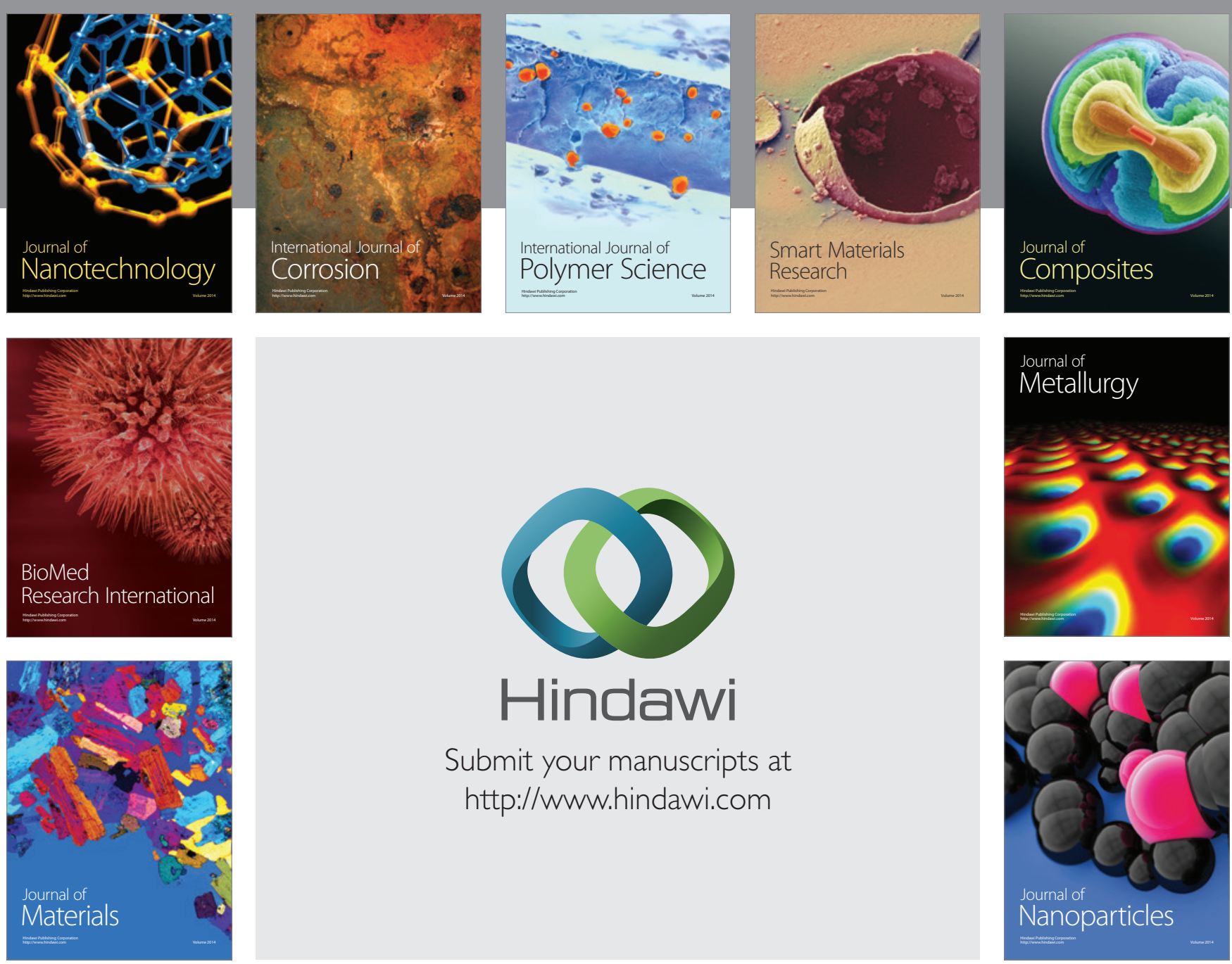

Submit your manuscripts at http://www.hindawi.com
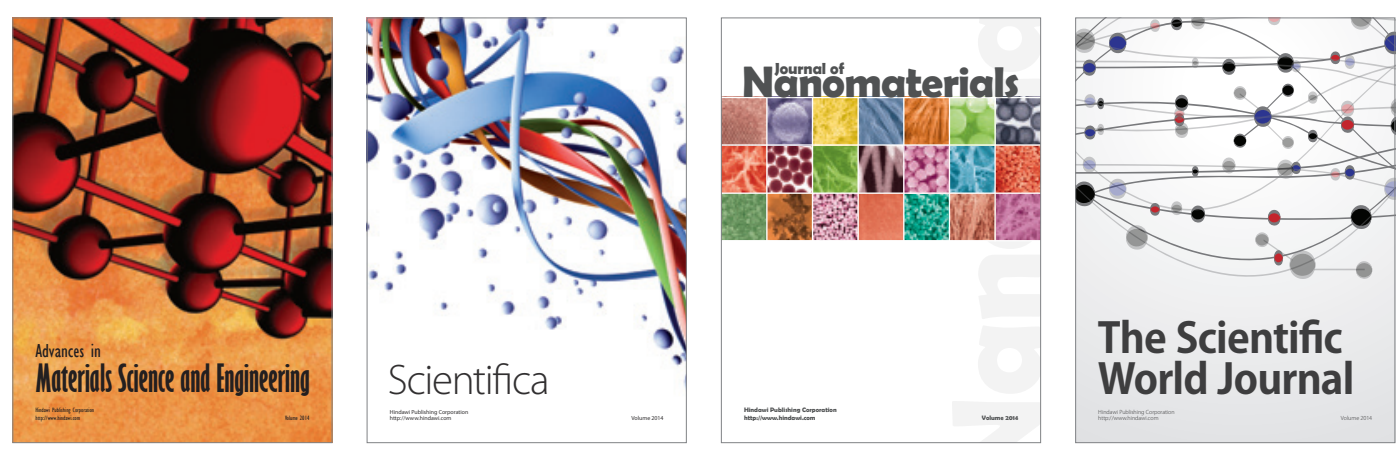

\section{The Scientific World Journal}
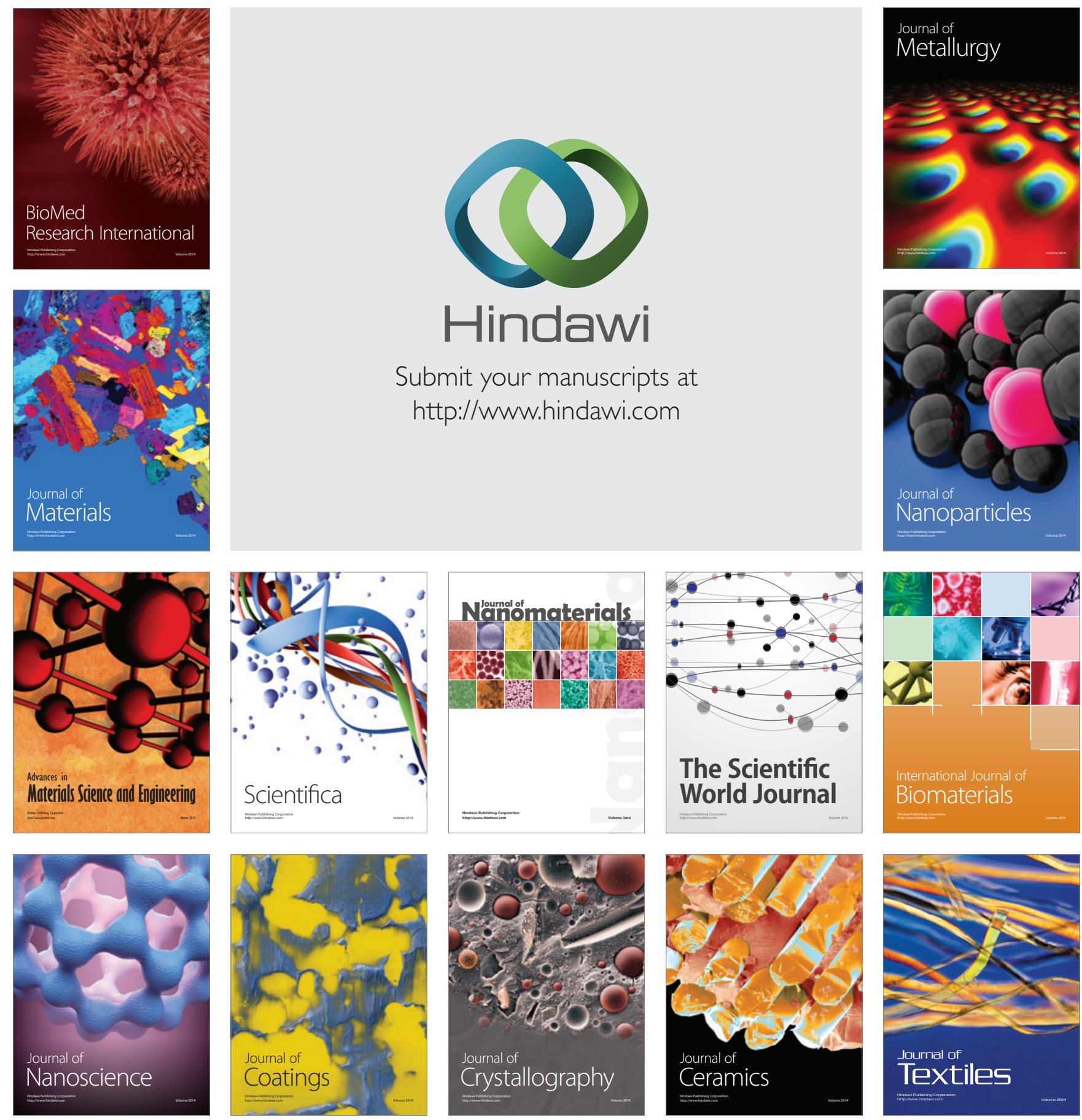